\title{
Epistemic Diversity and the Question of Lingua Franca in Science and Philosophy
}

\author{
Federico Gobbo $^{1}$ (D) . Federica Russo ${ }^{2}$ (D)
}

Published online: 30 October 2019

(c) The Author(s) 2019

\begin{abstract}
Epistemic diversity is the ability or possibility of producing diverse and rich epistemic apparati to make sense of the world around us. In this paper we discuss whether, and to what extent, different conceptions of knowledge — notably as 'justified true belief' and as 'distributed and embodied cognition'-hinder or foster epistemic diversity. We then link this discussion to the widespread move in science and philosophy towards monolingual disciplinary environments. We argue that English, despite all appearance, is no Lingua Franca, and we give reasons why epistemic diversity is also deeply hindered is monolingual contexts. Finally, we sketch a proposal for multilingual academia where epistemic diversity is thereby fostered.
\end{abstract}

Keywords Epistemic diversity $\cdot$ Lingua Franca $\cdot$ Language of science $\cdot$ Linguistic justice

\section{Knowledge and Epistemic Diversity}

A core philosophical question concerns understanding what knowledge is. This has occupied large part of the philosophical enterprise since the ancient times and is still a vibrant area of research within different philosophical traditions. Related to the question of what knowledge is, there is also the question of how to build knowledge, which can be thought of being at the core of scientific method on the one hand, and of philosophical argumentation on the other hand. These two questions - what knowledge is and how to build it-must be somehow connected. It is in fact dubious to have a theory of knowledge in which the what and how questions are unrelated. Yet, how exactly they are connected is contentious and one might wonder whether the second should be derived from the first, or vice versa.

Federica Russo

F.Russo@uva.nl

Federico Gobbo

F.Gobbo@uva.nl

1 Amsterdam Center for Language and Communication (ACLC), University of Amsterdam, Amsterdam, Netherlands

2 Department of Philosophy and Institute for Logic, Language and Computation (ILLC), University of Amsterdam, Amsterdam, Netherlands 
In the first part of the paper we explore whether and to what extent different conceptions of knowledge lead to different ways of building it. Specifically, we take issue with the still dominant view in analytic philosophy that sees knowledge as justified true belief (for short, JTB) and with the styles of argumentation (i.e., the way in which philosophy builds knowledge) that stem from it. We then examine the prospects of a different view of knowledge, notably as distributed and embodied cognition, and of a different way of building arguments. Our investigation into a different conception of knowledge and into a different way of building it is motivated by the idea of fostering epistemic diversity, which seems to be hindered by JTB. We think that an altogether different view on knowledge has important practical implications, for instance about assessment criteria (say, in peer review) or in handling disagreement (in philosophy and elsewhere).

In the second part of the paper we connect the question of how to conceive of knowledge to questions related to the working language in which they happen. We submit that this connection is not done in the literature and we offer reasons for its importance, relevance, and timeliness. In particular, we wish to broaden the perspective and problematize the question of epistemic diversity as a possible effect of what we deem a dangerous trend: the move towards monolingual disciplinary environments. We take analytic philosophy (which Anglo-American philosophy of science belongs to) as a paradigmatic example of such tendency, although such move is visible in philosophy more generally, and certainly in the sciences. While the search for the perfect language has been a long-standing objective of science and of philosophy itself, the very notion of 'Lingua Franca' should be problematized. We show that a monolingual environment is not only detrimental to knowledge production itself (whence our worry about epistemic diversity), but is also not in line with most present and past realities in philosophy and in science, which are instead multilingual. We therefore raise the issue of linguistic justice as an important concern for communication in philosophy and in science, one that is deeply connected to the questions of knowledge, discussed the first part of the paper.

\section{Epistemic Diversity}

We call 'epistemic diversity' the ability or possibility of producing diverse and rich epistemic apparati to make sense of the world around us. Such epistemic apparati may be sophisticated philosophical conceptualisations or theories, or their corresponding folk theories that each one of us has, in virtue of their experience as epistemic agent and language user in given cultural contexts. In this section, we discuss how differente conceptions of knowledge may hinder or foster epistemic diversity; subsequently, we link this discussion to the widespread move in philosophy and science towards a monolingual disciplinary environment.

A central concept in philosophy is 'knowledge'. Arguably, answering the question of what knowledge is (or, differently put, understanding what knowledge is) is not independent from the ways in which we build knowledge (which, admittedly, is a question at the core of philosophical argumentation and of scientific method).

According to an established tradition in philosophy, to understand what knowledge is means to state the conditions under which we have knowledge of a given proposition. We speak then of 'propositional knowledge', and knowledge is, in this approach, a justified true belief (JTB). While JTB had been effectively refuted already by Gettier, the view is still dominant in that it drives large part of contemporary research in 
epistemology. Specifically, in analytic philosophy, 'knowledge' is typically analysed as follows:

A subject $S$ knows that $p$ if, and only if:

1. $p$ is true,

2. $S$ believes that $p$,

3. $S$ is justified in believing in $p$.

Critical aspects of this analysis have been identified as early as 1963 in the well known study of Gettier (1963). And yet, analytic philosophy has been hard working in providing conditions and specifications that would make the previous analysis correct or at least viable. We lack space to make justice to the sophisticated and elaborated philosophical production to defend this idea, and we direct the reader to the thorough introductions to this view and to the corresponding debates by Ichikawa and Steup (2017) and Steup (2017). Despite the well known critical aspects of JTB, the view is still on today's research agenda (see e.g. Turri 2012; Kraft 2012, or Dutant 2015); at the same time, altogether different views are explored, for instance in the philosophy of information (see e.g. Dretske 1983, 2008; Floridi 2004, 2012). JTB presupposes that knowledge is propositional-whether it is mainly, solely, or perhaps essentially propositional does not matter here. What does matter is that, because knowledge is expressed propositionally, one can say under what conditions a subject $S$ knows something ('that $p$ '). Implicit in the analysis is that subjects are individuals, often idealised and fully rational epistemic agents, and that 'to know that $p$ ' requires some form of correspondence between the proposition $(p)$ and the world (a state of affair, a fact, etc.) - on theories of truth and especially on the correspondence theory, see David (2016).

Now, while analyses along those lines have the clear merit of being precise, rigorous, and neat, one might wonder whether, to maintain such a high level of conceptual rigour, we are also paying a high price. In particular, one might wonder who this epistemic agent is and whether s/he is far too idealised, or whether a correspondence theory of truth provides an adequate account of the relations between our language and the world (for an example of such criticism, see Radder 2017). Another issue concerns the distinction between 'know that' and 'know how'; in the 'intellectualist' approach of Stanley and Williamson (2001) and of Stanley (2011), 'knowing how' is a form of answering questions to be expressed in propositions. It should be noted in that the critical assessment of Radder (2017) also concerns the 'materiality' of 'know how', which in his view cannot be fully accounted for with a propositional concept of knowledge. In fact, the 'materiality' of knowledge is an aspect that non-analytic philosophers of science also paid attention to, see e.g. Baird (2004).

It is not our intention to enter the debate and to weight the merit or shortcomings of the many debates around propositional concepts of knowledge. Instead, we wish to establish a link between what knowledge is and how to build it. In particular, embracing some form of JTB leads to producing knowledge (i.e. building arguments) that hinders, rather than fosters, epistemic diversity. In this section, we highlight reasons related to the preferred argumentation strategies; later in the paper, we also give reasons related to working in a monolingual rather than multilingual academic environment.

To see how that may be the case, one may browse serendipically mainstream journals in analytic philosophy (including Anglo-American philosophy of science). The way in which, 
in philosophy, we produce knowledge is by designing arguments to the effect that a given claim is well supported by evidence and by given inferential rules. It won't take long to recognise patterns in the set up of an article's argumentation strategy. Ideas are often presented rhetorically as logical consequences of a given set of premises, as negative results established from an analysis of a competing view or theory, or as knock-down counterexamples to a proposed view or account. What we take issue with is not the rigour in the thinking. One motivation of the founding scholars of analytic philosophy was the insistence on a precise, rigorous, and empirically-based reasoning. This, we believe, has value. Also, there is of course value in discovering mistakes and pointing them out. What we take issue with is in case the only goal is to prove a negative point, with no contextualisation of why the mistake needs to be corrected.

Let us emphasise, we are far from trying to demonise analytic philosophy. What we take issue with is the standardization of argumentation, which, we think, hinders epistemic diversity. Arguments do come in a variety of forms-Millgram (2001), for instance, surveys the ones used in practical reasoning and makes the point that choosing one or the one may have important repercussions on ethical theory or other areas. But analytic philosophy de facto limited the admissible ones.

As Preston (2010) has noticed, analytic philosophy became somehow victim of its own commendable principles: rigour became a value on its own, at the expenses of the contents. In a similar vein, van Inwagen (2006) seems to suggest that central to analytic philosophy is the (style of) analysis of concepts, and less their contents. Analogous remarks are likewise made by Schliesser in a recent blog post and interview. ${ }^{1}$ The level of technicality reached by present-day analytic contributions has greatly increased; however, this has also led to a debate that became much inward- rather than outward looking. A sign of this is the lack of self-reflection in the field, although the problem begins to be recognised, thanks especially to metaphilosophical discussions in experimental philosophy-see for instance the recent contributions of Nado (2016) and Machery (2017). In history and philosophy of science, instead, many sub-fields other than Anglo-American philosophy of science produced important reflections on their own identity, methods, or preferred topics-see, among others: Andler 2009; Boon 2017; Chang 1999; Longino 1987; Massimi 2009; Radder 1997; Schickore 2011; Schliesser 2006, 2011.

It is therefore in this sense that Preston (2010) talks about the illusion of analytic philosophy, because, somehow, it did not live up to its own standards (let alone reflect on them). To be fair, Preston also mentions the illusion of continental philosophy, but he doesn't quite develop it further. So perhaps, at the other end of the spectrum, another story ought to be told about the illusion of an all-and-only culture- and context-based continental philosophy. If one were to tell such a story, good places to start would definitively be D’Agostini (1997) and Glock (2008).

This standardization of argumentation de facto coincides with the use of English as the main (or sole) language for scientific communication. In Sect. 3, we try to reconstruct the lineage between the kinds of standardization of argumentation alluded above and the standardization of language. In the remaining part of this section we explore whether, and to what extent, a different conceptualization of knowledge may lead to a different way of building it, thus fostering epistemic diversity.

\footnotetext{
1 http://digressionsnimpressions.typepad.com/digressionsimpressions/2018/03/on-taboos-and-brutal-hones ty.html, https://epochemagazine.org/interview-adam-smith-as-systemic-philosopher-and-public-thinker$6829 \mathrm{a} 0749 \mathrm{~d} 04$.
} 
Alternative views of what knowledge is have been proposed in the fields of philosophy of information and of technology, and of cognitive science-see e.g. Floridi (2011a), Giere (2010), Leonelli (2014), Nersessian (2008), Russo (2016). What emerges from these contributions is that knowledge, rather than being reduced to the propositions in which we express it, is to be understood as a distributed and embodied phenomenon. Accounts of distributed and embodied cognition make the point that knowledge is not 'owned' by a single, individual agent, but is instead distributed across individuals and across groups of different epistemic agents (be they human, artificial, or hybrid). Knowledge is also distributed across socio-technical systems that we humans belong to. Our being part of these systems makes knowledge also embodied, in the sense that it is not merely or purely an intellectual, abstract 'thing', but very much part of our material relation with the surrounding world. In such a framework, knowledge is not simply about establishing the right sort of 'correspondence' with the world, but rather the right sort of connections. The correctness theory of truth developed in the philosophy of information helps here (Floridi 2011b), as it abandons a monolithic, absolute conception of truth, in favour of a concept that is relative to a given model for handling information, and does not require what Tarski called the 'classical conception' of truth, one that establishes a correspondence between language and reality.

Embracing a conception of knowledge as distributed and embodied cognition fosters epistemic diversity because we are forced to consider all sorts of non-propositional factors that may play a role at any step of the process of knowledge production: social and cultural relations, interaction with technology, the use of specific conceptual frameworks, and also the use of different vehicular languages. This is is much broader and inclusive than a merely propositional conception of knowledge. Interestingly enough, broadening the notion of knowledge beyond its propositional nature, may also shed light on classic debates in philosophy of science, notably about 'scientific progress'. According to Mizrahi (2013), for instance, scientific progress is more than a simple accumulation of true propositions. An (historically-informed) analysis of actual cases from the scientific practice shows, according to him, that (scientific) knowledge ought to include 'know-how' besides 'know-that'. We take Mizrahi's argument to lend support to our point, namely that knowledge is not to be reduced to propositions.

Given the large difference between the two approaches to knowledge, the question looms large: why going for distributed and embodied cognition, rather than JTB? From a philosophy of science perspective, it suffices to look at the practice of the sciences (and of philosophy too) to realize how much knowledge is a collective endeavour, where individuals interact with one another and with technological equipments (from labs to computers to digital humanities tools) in specific institutional and social settings. Knowledge, while clearly expressed in propositional form in academic publications and conferences, is not to be reduced to it. From a more distinctive philosophical perspective, such conception of knowledge is not trapped in the straightjacket of rigid argumentation strategies. While rigour should remain a fundamental value in philosophy and in science, we can here concentrate on the contents of the arguments rather than on their mere structure.

Take philosophical contributions as the hallmark of the way we build knowledge. What we propose below is not a rigid scheme to structure a paper or a conference presentation, but rather is a 'flexible epistemological strategy' to produce valuable philosophy. While at a first glance what follows can be seen as an oversimplification, we believe it captures the gist of a strategy that can go counter an increasingly individualistic and confrontational academic culture. 
To begin with, we should engage with a problem. Far too often we write papers that are narrow in scope, and that focus on details losing sight of a deeper problem that might lie behind. Why should we really care about taking issue with footnote $X$ in the paper $Y$ of Author $Z$ ? The footnote might be problematic, but if it is so, that must be explained with respect to a context. So, if there is a problem somewhere in the literature, we should say what we want to do with the problem: Analyse it? Solve it? Redress the debate? These are all different goals, and we should be clear about what we want to achieve in our contribution. Being clear about our goal will also help our readers engage with our project. Next, we should remember that we don't write and think in a vacuum. Acknowledging other people's contribution shows that there is an issue that the community is trying to address. We don't own problems, or solutions. The view of knowledge as distributed and embodied cognition also means that it is a collective enterprise and each one of us is contributing something to it, no matter how tiny the contribution may be. This is to say that, in this collective enterprise it is unclear what we gain in proving each other wrong. Instead, it is a much more constructive attitude to identify problems in order to attempt a solution. Finally, we should aim to take the debate a step further by putting forward a proposal. Most likely it is not going to be the end of the debate, and we should humbly assert what we think our tiny contribution to solving the problem is.

This strategy, we think, can shed light on how disagreement in philosophy ought to be handled. If the goal is not to prove each other's wrong, what do we disagree on? The epistemological strategy sketched above helps understand whether disagreement concerns, for instance, the reconstruction of state of the art, or the framing of the problem. Or perhaps it is about the relevance of the research question, or indeed about the contents of a proposed solution. In any of these cases we can contribute to make progress, rather than concluding with a negative result. So negative results are indeed important, but they shouldn't be the goal of a philosophical project-the goal should instead be to positively contributing to a debate. Whether we make progress by establishing negative results also depends on how one understands progress in philosophy. We here take side with Floridi (2013), who conceives of a philosophical question as one that is inherently open-ended (and that can genuinely be informed by rational and honest disagreement); Floridi's position is however different from the 'reasonable optimism' defended by Stoljar (2017). We instead do not side with other scholars such as Chalmers (2015), van Inwagen (2004), who think that progress is made by gradually converging towards truth - and that, they argue, isn't quite happening in philosophy.

All this does not imply that we will always reach consensus, but it encourages a respectful interaction where we acknowledge disagreement, rather than demonise or patronise the other party. So, even if disagreement is not resolved, we can learn something, for instance about differences in the contents, norms, or perspectives. This has obvious consequences for assessment criteria, for instance in peer-review. The goal is not to compromise on quality and rigour in thinking, but in opposing practices that are rapidly spreading. When reviewing a paper, we should ask ourselves the question whether we are attempting a constructive, critical assessment, or whether we are justifying aggressive, patronising, disrespectful arguments behind the protection of blind review. But also, we might question the meaning of prizes for the 'best paper'. What does 'best' mean? How do we assess brave papers that champion a new concept, or that attempt genuine inter- or trans-disciplinary dialogues? Or that try to get out of the ivory tower of philosophy and try to reach out, say, policy makers? The strategies to write a successful paper aimed at non-philosophers may diverge from the accepted norms and standards within the field. How do we assess such contributions? While it is beyond the scope and aims of this paper to provide recipes to 
address these issues, we believe it is nonetheless important to bring them to the fore for discussion.

The epistemological strategy we propose aims to promote diversity: about ideas, about traditions (philosophical or scientific), and also about language use. In fact, it is meant to facilitate and encourage inclusion of considerations about sociological aspects, values, or cultural components. After all, knowledge is not just propositional, and philosophical concepts (such as 'knowledge'), no matter how sharply can be defined, are not merely abstract and theoretical. Concepts and theories are products of our philosophical and scientific investigations, just as they are products of our cultures, and this includes language in a fundamental way.

The epistemological point we want to make about epistemic diversity is also related to the competitive, confrontational, and individualistic cultural that is becoming established in academia. We should instead develop (or perhaps rediscover) argumentations strategies that, in addressing any philosophical problems, foster dialogue and collegiality rather than individualistic and confrontational attitudes. We claim no originality in making this point, but we wish to add to arguments made already within feminist scholarship—see Easley (1997), Hundleby (2018), Rooney (2010) and references therein. Feminist argumentation theory takes issue with widespread argumentation styles that favour confrontation and individualistic attitudes. These contributions link such traits to gender aspects, and most probably this is not unrelated to well-known, heavy gender imbalances in philosophy (see Beebee and Saul 2011; Haslanger 2008; Hutchison 2013 and references therein). The need for a dialogical (rather than adversarial) form of argumentation is also discussed in logic and philosophical logic, as part of a debate on the nature and structure of arguments-see e.g. Dutilh Novaes (2015). In our view, the move towards monolingual disciplinary environments (therefore raising the question of English as Lingua Franca) adds another perspective to the arguments offered within this literature.

One may rebut that, however, the view of knowledge as distributed and embodied cognition is a product of Anglo-American academe, which is written in English. Indeed it is, but with an important qualification. Many of these scholars, who do care about epistemic diversity, do not work in 'mainstream' philosophy of science, but rather in other philosophical schools such as 'philosophy of science in practice', 'history and philosophy of science', or 'philosophy of information', all of which tried, in different ways, to re-open the doors of philosophy to neighbouring disciplines in the sciences and in the humanities. More to the point, one could say that, notwithstanding the hard battles to establish such results in Anglo-American debates, similar ideas were already circulating in non-English speaking philosophy previously and almost unnoticed-the contributions of Merleau-Ponty, or of the French epistemologists, from Bachelard to Latour, come to mind. So we'd better make our language policy as open as possible to (re)integrate non-English traditions, contrasting the current tendency with a more balanced multilingual strategy, that we will present in the concluding section.

From a more sociological perspective, in academic as well as everyday settings, we routinely build connections with other people's work, getting feedback on written pieces or on presentations. In short: it is never just our own idea, expressed in the form of 'that $p$ '. We might have gotten the wrong impression that ideas belong to single individual minds from reconstructions of the history of philosophy, which depicted the complex conceptual architectures of say, Leibniz or Kant, and that therefore return to us only a partial image of the philosophical enterprise. For one thing, these thinkers entertained relations with other intellectuals (from other cultures and speaking other languages) of their time that are far too often neglected. For another, and relatedly, far too often women have been excluded 
from these histories, thus conveying the idea that philosophy is a 'male thing', requiring skills that men, more than women, have (see e.g. Broad 2015).

For all these reasons, we submit that the epistemological approach to knowledge production just sketched can be the basis for a multilingual academic environment and editorial policies, as discussed later in the paper.

We began the discussion of epistemic diversity raising genuine philosophical questions about the nature of knowledge and of the way of producing it (in philosophy, this largely coincide with building arguments). But ultimately our aim is to connect a genuine philosophical problem with a more a historically- and sociologically-oriented issue, namely how and why philosophy and science by and large shifted towards a mono-lingual environment. Our goal is to show that the language in which we express knowledge has a deep influence on epistemic diversity.

\section{From Multilingual to Monolingual Disciplinary Environments}

The majority of today's scholars, regardless of their field, take for granted that English is the language of science, a Lingua Franca for different language users, including non-native speakers. Philosophy is no exception in this respect. But this was not always the case. With 'language(s) of science' we mean here the languages used to publish innovative results in the various scientific disciplines, therefore excluding textbooks and other didactic materials, as well as translations.

There is an important question related to how we should set up didactic programmes that increasingly attract (or aim to attract) international students. This is - at the time of writing - the object of a vivid controversy in academia. The debate raised by the expansion of English in teaching programmes of universities in Nordic countries - see Airey et al. (2017) — and the recent verdict in Italy—see the recent Salomone (2018)—are just two examples of why it is high time to have a thorough discussion about the viability or desirability of 'English-only' programmes. The Erasmus programme of the EU is also a good example: born to promote exchange between cultures and languages at university level, in practice student mobility nowadays happens only where universities offer courses in English. While we think that these issues ought to be urgently addressed, we defer a full discussion to another time, and here concentrate on knowledge production at the level of research.

In a series of publications, Ulrich Ammon investigates the languages of science used throughout the twentieth century (Ammon 1999, 2001, 2006). He shows that the relative equilibrium that the languages of science-i.e. German, French and English, in this order of importance-reached in the early years of the twentieth century was lost in the aftermath of the First World War. Although Ammon's studies focus on the languages of science it seems plausible that philosophy too was in an analogue situation (van Weijen 2013). Back then, the quest for a neutral language of science (and diplomacy, in order to foster peace among nations) was part of the discussion of public opinion. The adjective 'neutral' here addresses the need of a non-ethnic language, planned ad hoc for communication among speakers of different mother tongues, following a positivistic idea of culture-free neutrality. In the terminology of those times, such languages, invented for ethical purposes, were called International Auxiliary Languages (IALs, for short; see Sect. 4). Two of them, Esperanto and Ido, have been used for a couple of decades as languages of science with non-irrelevant numbers-see de Kloe (2016), Gordin (2015). In particular, Esperanto is 
still used today as a language of science-even if with tiny numbers compared to English-and there is even a university institution in San Marino that uses Esperanto as the main working language (Gobbo and Fößmeier 2012).

The main point we want to stress here is the fact that the term 'neutral' used for IALs is very different from 'franca' in the case of the Lingua Franca. In fact, while in the case of a IAL, such as Esperanto, freedom comes as an a priori property, in the case of Lingua Franca the (supposed) freedom comes only a posteriori, because of the spread of an idiom which emerged originally from a well-defined ethnic group, i.e. English. As we will see in detail in Sect. 4, English as a Lingua Franca attempts to avoid all the consequences of discrimination and unfair advantage of English per se; and yet, native speakers are de jure and de facto in a more privileged position, compared to non-native speakers.

In order to exemplify what stated until now, let's take the case of analytic philosophy. Analytic philosophy speaks English. This is a fact. But why is it so? This requires some attention and, as we shall see in elucidating the reasons that led analytic philosophers to speak English, this choice can be problematized, and suggestions for a multilingual setting can be formulated. Here, we analyse the case of 'English in analytic philosophy' as one of the languages of science, as defined above. As it will become clear throughout the discussion, the (implicit) language policy of analytic philosophy highly influenced the research agenda of the field. It is reasonable to think that analogous arguments hold for other subfields in philosophy and for the sciences.

Analytic philosophy is a sub-discipline of philosophy typically associated with the work scholars based in the United Kingdom, United States, and Australia. It is often contrasted with 'continental philosophy', which is instead practiced on the European continent (and surely elsewhere). In using the term 'analytic philosophy', we broadly refer to (analytic) philosophy of language, (analytic) ontology, philosophy of mind, and also (analytic or Anglo-American) philosophy of science. The geographical distribution of these philosophical sub-fields is typically associated with the main working language on the one hand, and with preferred topics and approaches on the other hand. A thorough reconstruction of the analytic-continental divide in all its historical, conceptual, sociological, and institutional subtleties is well beyond the scope of this paper; useful historico-philosophical reconstructions can be found in e.g. D'Agostini (1997), Glock (2008), Preston (2010, 2017), and for a bold attempt of reconciliation, see Barris (2012). We are here interested in a drawing the main line that lead fields in philosophy from multi-lingual to largely mono-lingual environments. To this end, we recall two important episodes that led English to be the main-and perhaps sole-working language of contemporary analytic philosophy.

The first episode is the emergence of analytic philosophy in the early days of the twentieth century; the leading figures of George Edward Moore and Bertrand Russell are generally acknowledged as the founding fathers. From a methodological point of view, the main change is the central role given to the linguistic analysis. For Russell, in particular, natural languages are inherently ambiguous and therefore philosophical inquiries should not only work on their object of interest, but also at the meta-level of the language used to reason over the object itself. In particular, Russell resumed and actualized Leibniz's programme (Calculemus!) and tried to define a formal language expressed in terms of symbolic logic. He thought that true meaning of statements could be revealed through their logical form and by using Peano's notation, whom he met during the International Congress of Philosophy in Paris in 1900. Russell famously said that that was "the most important year of my intellectual life" (Russell 1989, 12). Even if we know that his line of research, culminating in the Principia Mathematica, did not succeed because of the fundamental results established by Kurt Gödel (see Davis 2000), Russell never considered English language to be 
the one and only possible natural language for expressing the commentaries on the statements in the formal language. Despite it was not part of Russell's philosophy to impose English as the sole object of study of philosophy of language, English effectively became both the main working language and the object of study in the analytic philosophy that originated from his work. In Russell's times, moreover, there was a vivid debate among philosophers, scientists, and scholars in general on the role played by the various languages used in science, most notably French, German and English (in this very order of importance), with a more marginal role of Italian, Spanish, Russian and Japanese, and a discussion about IALs such as Esperanto and Ido (see Gordin 2015).

Ironically enough, over the years, the more 'language' became the object and the main instrument to do analytic philosophy, the more English became the language of the field. In fact, the fortunes of the school of analytic philosophy will be mainly in British and North American universities and research institutions, and therefore the use of English as the vehicle for transmission of analytic philosophical ideas became predominant and unchallenged, especially in the aftermath of the Second World War, where the focus shifted towards the analysis of ordinary language, with Austin (1962) and Searle (1969) paving the way. The topics of analytic philosophy also became highly language-dependent: presuppositions and inferences that are implicitly coded into English depend on the way English wraps up the meaning, while in other natural languages other presuppositions and inferences can be found, not necessarily coinciding with the English ones. In 1960, Gustav Bergmann introduced the expression 'the linguistic turn' to describe the change of focus towards language done by analytic philosophy since at least Wittgenstein's Tractatus (see Hacker 2013). Since then, in analytic philosophy, English has been simply taken for granted. In this respect, analytical philosophy has been more Catholic than the Pope, while other branches of philosophy, as well as science in general, did not accept this monopolistic role of English until the 1990s (see the work of Ammon (1999, 2001, 2006), that provides aggregate data for publications in the fields of biology, chemistry, physics, medicine, and mathematics).

The second episode we wish to mention is the migration of leading figures in philosophy of science and in science from German-speaking countries to English-speaking countries, particularly those places that now coincide with key analytic philosophy hubs. This happened, as the reader will have guessed, during the critical period that preceded the Second World War, specifically from 1933, when Hitler gained power in Germany. This massive migration widely affected (Jewish) scientists from different fields, from medicine to physics, from sociology to pedagogy, and philosophers (Ash and Söllner 2002). The episode is worth mentioning for two reasons.

First, many of the scholars who migrated were philosophers and scientists engaged in the activities of the Vienna Circle. Eminent thinkers such as Carnap, Neurath, or Gödel left continental Europe and continued their career in the Anglo-American World. One thing these philosophers were interested in was developing a rigorous empirical philosophy, far from untestable metaphysical theses, and capable of gradually building a universal knowledge; an explicit critical target was the philosophy of Martin Heidegger, attacked by Carnap (1932), in an article originally published in German, and translated into English only much later. Vienna Circle philosophers contributed to identifying 'good' philosophy with rigorous, formalizable, or formalized reasoning. A notable example in this endeavour is the Vienna Circle manifesto (Neurath 1973) and the idea of a planned International Encyclopædia of Unified Science. Much of present-day analytic philosophy, and also what is now called 'formal philosophy' or 'mathematical philosophy', stems from the philosophy of the Vienna Circle (see e.g. Horsten and Douven 2008 or Leitgeb 2013; for a pluralistic 
plea, instead, see Haack 2005). This is not to establish a lineage between the emigrated Vienna Circle philosophers with the the widespread standardisation in argumentation typical of contemporary analytic philosophy (that we criticised earlier in Sect. 2), but rather to explain how this philosophical tradition-in the beginning rather multi-lingual and certainly not hostile to viewing science and knowledge as distributed or embodied-came to speak English.

Second, that English is the de facto 'official' language of analytic philosophy is a clear historical contingency, but important for our discussion: these philosophers and scientists active in Vienna and Austria were German native speakers, who only later used English as their main working language, once they migrated. This might seem an innocent remark but Wolters (2015) notes that in a widely read and distributed pedagogical resource as The Cambridge Dictionary of Philosophy, the entry 'logical positivism' does not appropriately acknowledge its Austrian-German roots, merely alluding at British roots via British empiricism - whose main representative is, admittedly, Bertrand Russell. So, suddenly, big chunks of influential and fundamental philosophical traditions are obfuscated behind the Anglo-American ones. This creates historical distortions that may have important repercussions for younger scholars approaching the field. Moreover, that the research agenda of philosophy of science was set by exclusively English speaking scholarship was also noted already in 2008 by McAllister (2008).

One might think the migration of German-speaking scholars to English-speaking countries should have favoured the circulation of ideas, thus contributing to epistemic diversity. To some extent this is correct, and is also evidenced by historical investigations on circulation of knowledge and migration (see e.g. Hoch and Platt 1993). However, what has been observed since then, is a gradual takeover of English as the main working language and of the methods of analytic philosophy as the preferred ones, thus leading to a de facto standardization of philosophical jargon and of argumentation strategies. No doubt these are also effects of the widespread publish-or-perish culture: we need as many research outputs published, and in internationally recognised venues. As it turns out, publication venues with the highest reputation publish (only) in English, as evidenced by the main international rankings, where at the top there are mainly_or even only-venues coming from Englishspeaking countries.

This rather long preamble serves to establish the following points. First, it is a (historical) contingency that analytic philosophy came to speak English-there is no a priori or theoretical reason for why it should be so. For instance, Vienna Circle philosophers entertained academic relations outside the German-speaking world—see e.g. Stadler (2007). Second, and relatedly, the analytic-inclined philosophers and scientists on the continent used to work in a multilingual setting while launching the discipline.

When looking at the de facto linguistic monopoly of English in analytic philosophy, two main issues may be raised, which really concern the whole of philosophy and of science. The first issue comes from the perspective of sociolinguistics and in particular linguistic justice: a whole-and-only English speaking academic community creates profound injustices among its community members, precisely for non-native speakers. In the context of analytic philosophy, English is often referred to as a Lingua Franca. However, we are sceptical that this is the function English really serves in scientific communication nowadays. Thus, Sect. 4 discusses and problematizes the notion of Lingua Franca, and Sect. 5 presents the main philosophical positions on the current debate on linguistic justice, in relation to the problem of the language(s) of science. The second issue comes from an epistemological perspective. We think that the exclusive use of English greatly restricts the options for developing rich and sophisticated conceptual apparati, as the knowledge we 
produce is intimately linked to the linguistic, epistemic, and socio-cultural instruments that we use. This was discussed earlier in Sects. 1 and 2, with explicit reference to the notion of 'knowledge'. In both Sects. 4 and 5, we put forward proposals to minimise linguistic injustices and to foster epistemic diversity. In the concluding section we further reflect on the feasibility of our proposals and on the value of our problematization of English as a Lingua Franca... which ironically is happening in English.

\section{What Does the Expression 'Lingua Franca' Really Mean?}

The expression 'lingua franca' comes from Latin; its precise etymology is unclear (Brosch 2015), but it is generally interpreted as a synonym of 'free language'. It was proposed originally by Hugo Schuchardt, the German linguist pioneer in the studies of contact languages such as pidgins (Schuchardt 1909), creoles (Schuchardt 1979), and International Auxiliary Languages (IALs) such as Volapük (Schuchardt 1888). In fact, for him, the lingua franca was a Vermittlungssprache, a 'mediation language', that emerged because of the trading in the Mediterranean Sea during the Middle Ages between speakers of Romance languages such as Castilian, Catalan, Provençal, Ligurian, Venetan, once in contact with Arabs and Turks. It was a sort of unstable pidgin for the domain-specific purpose of trading. The original lingua franca was a mediation language between speakers of different mother tongues and identities. Nobody owned it, and this is the implication of the adjective franca-free-from any ownership, in particular from the native speaker's authority that stays behind most Kultursprachen, cultural languages, such as German, French or Italian. The expression 'Lingua Franca'-regardless whether it is used for English or other languages-entails this claim of ethnic freedom.

The scholarly literature on English as a Lingua Franca (ELF)—represented in particular by Barbara Seidlehofer (2011) and Jennifer Jenkins (2007)—reframed Schuchardt's expression advocating that English is neither the property of the English people nor of any other ethnic group because of its terrific spread. A first argument, put forward by the supporters of ELF, is the number of non-native speakers of English. In fact, according to David Crystal, already in the early years of the new Millennium, the number of non-native speakers outnumbers native speakers by a ratio 3-1 (Crystal 2003). A second argument, directly connected to the first, is the question of authority: English natives do not hold anymore the ownership of the English language because they are outnumbered. In the same period, David Graddol introduced the idea of the 'decline of the [English] native speaker' in shaping the authoritative norms of usage (Graddol 2003).

So, paradoxically, the emergence of 'New Englishes' would reduce if not eliminate the unfair privileged position of English natives in their communication with non-natives. The expression 'New Englishes' refers to self-standing varieties of English in different areas of the world-in most cases post-colonial, but in the last decades referred to the use of English in the European continent too. However, the literature on World Englishes shows that these varieties are not norm-providing, unlike English in its proper language territoryi.e., UK, US, Canada, Australia and New Zealand. On the contrary, World Englishes are norm-developing, when they come from post-colonial countries, such as India, Nigeria, the Philippines. The situation is however different if we analyse the English varieties used in contexts where other national languages strongly shaped national identities, such as most countries in the European continent: all these English varieties are clearly norm-dependent 
from the strongest standard varieties, i.e. General American and Standard British English (Krachu 1992).

This is all to say that ELF is not a self-standing variety of English but a communicative strategy used when interactions occur between non-native speakers that in some contexts form norm-dependent or norm-developing varieties of English. An important consequence is that the authority of these English varieties cannot compete with General American English or Standard British English. Therefore, on a global level, the power of the English native speaker still holds. In other words, English is never free from the authority of its native speaker, and the expression Lingua Franca used in relation to it is merely metaphorical, running the risk of making things opaque rather than clear.

We can ask ourselves if it is possible, in principle, to have a real Lingua Franca, namely a language that is no-one's property and that potentially belongs to everybody, because no authority of native speakers exists. What Schuhardt called (in German) a Vermittlungssprache 'mediation language', as we have seen above, is nowadays generally referred as 'pidgin' by contemporary linguists. The original lingua franca spoken in the Mediterranean Sea was a contact language used for the domain-specific purpose of trading. Therefore, it fulfilled the requisites of having a truly ethnically free language: it had no native speaker and there was no authority whatsoever controlling or monitoring the language, so everybody was welcomed in using it. On the other hand, this freedom came with a high price: the original lingua franca was not equipollent to the Kunstsprachen, culture languages, that we consider the yardstick for judging 'languagehood', e.g. English, French, Chinese or Arabic. In principle, culture languages can be used for expressing all facets of human experience and the world of nature. This is a prerequisite in the case of scientific communication: the linguistic vehicles of expressing new ideas or innovative results cannot present internal limitations. Clearly, the original lingua franca, and pidgins in general, do not respect this requisite. In fact, the club of the languages of science is very exclusive: according to Ethnologue, there are currently more than 7000 living languages in the world; however, if we check all the original scientific production-even in a large sense, including Western and Eastern antiquity - the languages of science in all the history of humankind are less than 20 (Gordin 2015, Ch. 1).

At the end of the nineteenth century, the search of the perfect language that founded the European culture produced a plethora of language projects planned to fulfil the role of the language of science (Eco 1993). These language projects were often designed specifically to become a language of science if not the main one, and they all shared two properties. First, they were 'international', meaning that they did not belong to any nations: they were ethnically free; second, they were considered 'auxiliary', meaning that they should be used mainly for written purposes and in particular for scientific communication, without the aim to replace existing languages, and in particular national languages. Because of these two properties, during the first half of the twentieth century they were collectively called International Auxiliary Languages (IALs) — for a classic account, see Large (1985).

Unfortunately, only a dozen or so were put in use in practice in order to be tested for this important function, such as Peano's Latino sine Flexione, Couturat's Ido, IALA's Interlingua; however, only one did succeed to form a stable community of practice, showing that a general-purpose planned language is not a philosopher's dream but a human reality, that is Esperanto (Gobbo 2015). Are IALs in general, and Esperanto in particular, good candidates for fulfilling the role of the real Lingua Franca, specifically for scientific communication? From an epistemological point of view, unlike English or any other national languages, they are a priori ethnically free, that is no special ethnic group can claim for itself the property of these languages. However, in the case of Esperanto it is also true that 
the community of practice holds the language: in order to become a fluent speaker of Esperanto, the learner should enter the community, as there are some metaphors, expressions and even idioms that are built inside the community and they cannot be easily understood externally, or even translated, without an extensive commentary (Fiedler 1999). Moreover, there are more or less one thousand families who speak Esperanto at home, and, even if these bilingual Esperanto speakers do not play a distinct role in terms of authority on the language, according to some commentators, they challenge the ethnic neutrality of the language - see for instance, Fiedler (2012). The sociolinguistic reality of Esperanto in the twenty-first century shows that the Esperanto community succeeded in building a small but vivid non-national culture that voids the positivistic claim that IALs are, by definition, culture-free. However, the Esperanto culture is secondary, as any Esperanto speakers belong to at least one other language community-as monolingual Esperanto speakers simply do not exist - and they live most of the time in societies using languages others than Esperanto. In practice, for most aspects of everyday life, the culture of reference for an Esperanto speaker is not the Esperanto culture.

We can prudently conclude that no language is completely neutral, but Esperanto is somehow more neutral than others. This leads us to problematize the issue of linguistic justice, which is apparently not ensured by English, for it is not a Lingua Franca.

\section{Linguistic Justice in Scientific Communication}

The expression 'linguistic justice' is relatively new. It started being used in the 1990s, when the emergence of issues of language diversity recognition received the attention of political philosophers, dealing with the principles behind the design of language policy actions. In this sense, linguistic justice is modelled in a similar vain to socio-economic justice or environmental justice. An interesting line of research would be the investigation of the possible connections with with epistemic justice, as depicted by Fricker (2007), as the author's notion of identity power could be put in relation with linguistic justice, because of the role language has in shaping identity; however, such an investigation would require an entire new paper, therefore we cannot delve into it here. Although it is relatively new, there is already a considerable literature in the field, well presented by Alcalde $(2018,2015)$. According to the author, the notion of linguistic justice has no generally accepted definition because of the echoes of the liberalism-communitarianism debate that still divides the reflections in two approaches: the constitutivists understand languages as constitutive parts of identity construction of groups, while instrumentalists see languages as primary tools to perform non-linguistically defined things by single actors. While constitutivists tend to consider groups as legitimate agents in pursuing linguistic justice, instrumentalists generally see single individuals as the solely types of agents having the right to claim linguistic justice for themselves.

This distinction between constitutivists and instrumentalists still holds in the application of linguistic justice in scientific communication. This is a specialized domain of use, where 'internationality' is a crucial property that refers to cross-border communication between native speakers of different languages. Advocates of English-only policy typically put forward instrumentalist arguments; for instance, English is already the de facto vehicular language of science since the end of the Second World War, and English has traditionally been the language of analytic philosophy. It is important to note that one of the main arguments used by instrumentalists is that the emergence of only one language is inevitable 
for the need of efficiency in economies of scale: the more scientists are spread through the world, the more they need only one common language, in order to be fast and effective. This language happens to be English. In truth-as Robert Phillipson has shown in several publications - the expansion of English worldwide in higher education and, by extension, in research and science, was not an effect of free market, but a crucial part of Winston Churchill's political plan in the aftermath of the war (Phillipson 1992). However, in instrumentalist terms, political factors are irrelevant: the main point, relevant to our discussion, is that (English) monolingualism is put forward as the most viable solution-that is, efficient and fair at the same time-for international communication in every context. Philippe van Parijs (2011) brought this line of reasoning to its extreme consequences: for him, English is the necessary linguistic tool to achieve a global solidarity based on the equality of opportunities in mastering English, regardless of the territory of provenance. According to the author, this equality of opportunities can be achieved through a "global tax to the native English community" in order to compensate "the linguistically handicapped", i.e. people whose mother tongue is not English, who will "poach the web" as free riders to reduce their 'handicap'. Moreover, non-English governments should ban dubbing in shows so that the youngsters can improve their knowledge of the English language.

If we transpose this apologetic discourse around ELF within the context of publication of results in philosophy and in science, the result will be that such defence is simply untenable. First, as we have seen in Sect. 3, the research centres in analytical philosophy are mainly in Great Britain, North America, and Australia, not in places where World Englishes - in the sense illustrated above - are used, such as Pakistan or Nigeria. This means that no varieties of English can be accepted in scholarly publications other than British Standard English and/or American General English, and, according to our experience, this is by and large valid for all scientific disciplines. It has been suggested that the English register used in academic publication should be less strict, in order to reduce-to some extent - the unfair advantage held by colleagues having English as their respective mother tongue. Unfortunately, this seems not to be standard practice in the majority of journals we know of. We are in fact not aware of any peer-review journal that states in the Author's guidelines "we accept papers written in ELF". Therefore, in direct opposition to the Native English Tax that should eliminate the linguistic handicap and that van Parijs dreamt of, we face instead a real Academic Non-Native English Tax whenever an English non-native submits a manuscript for publication to any English-speaking venue.

This tax is paid in terms of money-outsourcing the proofreading to a professional native speaker-and in terms of time-writing through a non-native language slows down all the process, also because of a perpetual sense of linguistic insecurity, i.e. the feeling that the author's English register is not adequate for the readers who will evaluate it through the peer-review process.

If we mention the years a non-native spends to achieve a reasonable level of proficiency in academic English in contrast to a native speaker, it will be crystal clear that a native speaker will have lots of time-literally, years - to delve into the studying of the discipline instead of following English language courses or academic writing classes. To make the situation even worse, it should be mentioned the effort that many academics, expatriated from their original country, put in settling down in academic and every-day environments that do not speak English. Believe it or not, Dutch academia speaks Dutch, French academia speaks French, etc.-academic life is not just writing papers, but also admin meetings and teaching BA courses, all of which is most often done in the local, national language, rather than English. The point is that the concept of ELF is based on the false belief of freedom (from native speakers), which does not hold in the context of scientific 
communication. From the point of view of the constitutivist, the following argument can also be made: at the group level, the community of, say, analytic philosophers has become highly homogeneous also because of the unfair advantage English native scholars have in all the process that eventually leads to the publication of original research results (this can be easily checked by looking at who publishes in the top journals, who gets jobs in top departments, etc.).

Linguistic justice in scientific communication means that every actor in the process should not have unfair advantage because of their linguistic repertoire; however, this is in fact much dependent on the 'birthright lottery', i.e. the accidental circumstances of birth which have crucial consequences in terms of citizenship (Shachar 2009). If we apply a case scenario analysis on the basis of what we have said until now, we can figure out an ideal case, an undesired case, and a realistic case, which usually stands in the middle of the former two.

In an ideal scenario, all members of a given academic community should publish their results as bilingual original texts. One of the two languages would the language of their choice, typically their mother tongue, or in any case the Kultursprache in which they are most comfortable in. The other language should be the less non-neutral language ready for scientific communication we have at our disposal, namely Esperanto. In this way, they would use a linguistic medium that allows them a maximum efficiency while, on the other hand, the flexibility of Esperanto as a translation language permit to reproduce with reasonable approximation the content of the Kultursprache. Another advantage relies on the process of bilingual writing: the author is forced to jump from one language to the other, and in this multilingual process some peculiarities typically referred to the original culture of reference of the mother tongue will be removed, as they would be considered not 'international' enough. Of course, there is an obvious disadvantage in writing bilingually, regardless of the language: the time needed to produce the bilingual text is longer, at least double, than writing a monolingual text. And given the current burden of the publish-orperish culture (not to mention the increased admin and teaching load for both temporary and permanent staff), this is not a viable option. In any case, the ideal scenario is, as the word suggests, not feasible in practice, as it would require a complete change of route in the publication process of an entire discipline. Such a broad consensus in any given community is science-fiction, not science. Thus, the ideal scenario turns out to be, somehow, an undesirable scenario.

What we propose is a realistic scenario that keeps an open editorial line in linguistic terms. This allows us to retain the gist behind the ideal scenario: a multilingual strategy in writing the research results in philosophy and in science, will lead to better papers in terms of quality, improved because of the parallel text, as there are at least two cultural frames of reference to be taken into account in the production process. In more concrete terms, we would favour the reception of manuscripts written not just in English but also in any other recognised Kultursprachen such as French or German, with the addition of three abstracts, one in the language of the author's choice, one in the de facto international language, i.e. English, and the last one in Esperanto, for the sake of ethnic neutrality. As far as we know, this multilingual editorial policy is followed only by one academic journal devoted to language policy and planning issue, called Language Problems and Language Planning, https ://benjamins.com/\#catalog/journals/lplp/main), as a concrete message for accepting nonmainstream views on the topic. In philosophy of science, some journals follow a much milder multilingual policy, allowing for submissions in two languages; for instance, in principle, Erkenntnis accepts both German and English, Theoria both Spanish and English, 
Lato Sensu in French and English, Epistemologia in Italian and English. In fact, however, many of these journals are increasingly publishing in English only.

We submit that a multilingual solution, preserving multilingualism at least through the translation of abstracts, following the example of LPLP, should be applied to journals in philosophy and science. Such a solution would allow scholars to express more points of view linked to the cultural tradition of the different languages involved, and eventually it would lead to more epistemic diversity, which was our original concern in the paper. That knowledge is not just or solely propositional was our initial concern. We suggested that embracing a conception of knowledge as distributed and embodied fosters epistemic diversity. Distribution and embodiment, we submit, do include culture and, therefore, language. For this reasons knowledge production that happens in multilingual, rather than monolingual environment, should likewise contribute to fostering epistemic diversity, both in philosophy and in science.

\section{Multilingual Academic Environments: Back to the Future?}

It is a fact that philosophy and science speak English: mainly or solely, but certainly enough to pose the question about whether a monolingual philosophical tradition be desirable at all. There are interesting stories to be told about why it is so, and we mentioned two in Sect. 3: the linguistic turn in philosophy of language around the half of the last century and the migration of scholars (philosophers and scientists) from German-speaking countries to English-speaking countries before the Second World War. Although it is largely a historical contingency that a significant part of philosophy speaks English only, we find this problematic for two reasons: linguistic justice and epistemic diversity. Linguistic justice refers to the uneven conditions that different speakers encounter while speaking a same language: clearly English native speakers remain advantaged over non-native speakers, no matter how fluent we, non-native speakers, become. This means that English, contrary to what is usually thought, is no Lingua Franca. Epistemic diversity refers to the consequences that a monolingual situation has at the level of the epistemic apparati that speakers have or produce, in order to make sense of the world around us. These epistemic apparati may be sophisticated philosophies or folk worldviews each one of us has.

We explained that languages are non-neutral tools for the working philosopher or scientist; on the contrary, the choice of a language of science entails a reference to a whole school of thought, culture, norms, etc. This can be iconically represented by bibliographies - with a partial exception of this paper bibliography, which is mainly, but not entirely, in English. At the time of Bertrand Russell, when analytic philosophy was at its infancy stage, it was normal to have bibliographic entries of new philosophical and scientific papers in more than one language, including not only English, French and German but also Latin and sometimes Russian and Japanese. In contemporary philosophy and science, bibliographies contain too often English-only items. This produces a vicious circle: nobody reads anymore the research written in other languages, and therefore philosophers and scientists more and more publish their papers only in English, in order to gain attention by their communities of reference. We can call this phenomenon the tyranny of tradition.

In pursuing the English-only policy, we obtain that the access of some classics is severely limited in new generations of researchers who do not come-by chance, because of the birthright lottery-from multilingual societies, as their educational and research institutions do not value multilingualism as an asset for pursuing scientific research in 
general and analytic philosophy in particular. A typical example of this loss in the realm of science is the link between Russian and the Soviet school of science: after the fall of USSR the prestige of Russian was severely damaged at the international level; therefore, some scientific results were rediscovered only decades after in English, for the only reason that nobody had read the relevant literature in Russian, where the same results had been obtained well beforehand. A case in point is the interlingua model for machine translation by Soviet pioneer Troyanskii, as shown by Hutchins and Evgenii (2000).

Behind the concept of Lingua Franca there is not only the idea that such a language is supposed to be franca, i.e. a posteriori ethnically free, but there is also the idea that using a language or another in order to express oneself is basically the same in terms of expressiveness. If it is true that potentially all languages can express every nuance of the human experience, it is also true that some languages are more elaborated than others, if we take domains of use as the reference. Hypothetically speaking, a language spoken by a population living in a tropical island with no mountains will have a lot of lexicon about navigation and no word for "snow". This does not imply that that hypothetical population cannot invent a word for "snow" when they happen to have the new experience. So, a language will be more apt to express philosophy and science if such domains already exist in its history, in other words, if philosophical and scientific communication were already published in that language.

Although some scientific publications in Esperanto and other IALs do exist, Kultursprachen such as English, French and German have much more tradition. However, if this argument of tradition is pushed to its limits, it will turn out that, in philosophy (as well as science), only English will be the language ready off-the-shelf to publish all the nuances of the discipline. This clearly goes in a direction opposite to the one we have indicated, and one that will heavily hinder epistemic diversity. Instead, we think that multilingual environments are part and parcel of the way in which we produce knowledge. Knowledge, as we argued in Sect. 2, is a distributed and embodied phenomenon also at the level of language.

Our purpose was to reflect on the current limits of monolingual academic environments, which analytic philosophy is an example of, and to make practical suggestions to improve on a situation that we deem problematic. To get out of the monolingual impasse, we proposed a multilingual strategy according to which a liberal editorial policy allows publication of articles not only in English but also in any recognized Kultursprachen such as French or German, and abstract in three languages: one chosen by the author, English (as a de facto international language), and Esperanto (in the interest of ethnic neutrality). Luckily, just like nations, all languages are imagined (not imaginary) and therefore they can be planned and (re)shaped by their speech communities according to their needs. We think that the multilingual strategy we proposed can open the door to a more diverse community of philosophers and scientists, and foster, consequently, epistemic diversity.

At this point it is worth to briefly comment on the possibility of translating more, in order to compensate for the linguistic injustice introduced by the prominent use of English. Sometimes machine translation is evoked as a solution to all language problems, which eventually proved not to be, as the quest of a fully automatized, general-purpose, instant machine-only translation started since at least the 1950s (Léon 2002). That quest did not reach the sought results, and no serious research in Artificial Intelligence makes anymore such a promise nowadays. However, it is true that statistical machine translation and in general computer-assisted translation had achieved impressive results in the last decades (Koehn 2012). However, as these statistical-based engines are finally based on bilingual corpora available in digital form, the quality of the translation from and to English is fairly better compared to other languages. Thus, even in the case of machine translation, it is a 
driving force that ultimately brings to Englishization rather than to some more equitable form of multilingualism. The possibility that more translations of non-English texts (for instance in analytic philosophy, but also in other fields) may redress an otherwise unbalanced and unjust situation has been also discussed by Schliesser (2018). Yet, Schliesser is very careful in noticing that translations (and, a fortiori, machine translations too) are no panacea. For, just as any text is culturally-laden so is any translation of it. We agree with this argument.

The realistic scenario hereby sketched should be also accompanied by broad policies that encourage scholars to learn other languages as part of their education programmes, from Bachelor to PhD level and beyond. There is no shortcut guaranteed by digital technologies. The only feasible way is to rely on humans. Linguists have been saying it for decades: it is never too late to learn another language! We should also promote reading at least some primary literature in original language (if it is not in English). Perhaps there are interesting editorial projects to start. Finally, a number of 'best practices' fostering collegial and respectful behaviour are already in place, prompted especially by underrepresented groups in the profession, especially women (see e.g. swipuk.org). These best practices, which work quite well in conferences and seminars, may help mitigate linguistic injustice and foster epistemic diversity too. Analogous best practices may (or, perhaps, should) be extended to academic publishing.

Earlier in Sect. 3 we briefly mentioned that a thorough discussion about language policies also concern teaching in higher education. At the moment, in fact, in a number of nonEnglish speaking countries, heated debates are taking place about the bilingual or English-only programmes. In the Netherlands, for instance, the Faculty of Humanities at the University of Amsterdam published a Taalbeleid document - a document about language policy. ${ }^{2}$ Given the successful results of internationalisation strategies, the question arises about the taalvaardigheiden, i.e. the language skills that students ought to develop in their mother tongue (in this case, Dutch). The document suggests heading towards a bilingual faculty, where Dutch and English have the same importance. Notwithstanding the appeal of such resolution, conceptual and practical difficulties have been raised by students and staff members alike. For one thing, one should be careful not to sell 'internationalisation strategies' (which is really why universities push for developing programmes in English) under the label 'diversity'. For another, a bilingual environment would also increase the workload substantially (both for international staff, who should quickly reach proficiency in Dutch, and for national staff, who may not be proficient in English). ${ }^{3}$ In Italy, a recent verdict on the language of instruction at university level raised analogous concerns (Salomone 2018). It is worth noting that the perspective in Italy is different than in the Netherlands, as in Italy traditionally innovative research in the humanities - as well as in hard sciences, at least until the last two decades, following a tradition that starts from Galilei until Enrico Fermi-was made mostly (if not exclusively) in Italian.

The academic world is turning to a monolingual setting, which calls for appropriate reflection at linguistic and socio-linguistic level, at epistemological and pedagogical level,

\footnotetext{
2 The document, in Dutch, can be accessed here: http://www.uva.nl/shared-content/faculteiten/nl/faculteitder-geesteswetenschappen/evenementen/evenementen/2017/05/facultair-beraad-taalbeleid.html.

3 Analogous discussions are happening in other Dutch universities, too. See e.g. Groningen, Language Policy. An Inclusive, Dual-Plus Approach (2014); Utrecht, Stimuleringsproject verbetering taalvaardigheid (2015); Universitair Centrum voor Academische vaardigheden (2016); Free University Amsterdam, Taalbeleid VU: Naar een Integrale Aanpak, (2016). All these documents are downloadable from the web.
} 
and at historical level. We make here no claim to solve any issues, but we hope to contribute to a self-reflective exercise that we deem a valuable, and indeed necessary, step before any other measures in the linguistic policy in the academe is implemented. Ironically, one may say, the whole discussion in this paper is made in English. We are of course not rejecting English in toto, and if English is de facto the most used language in philosophy and in science, the point is worth making by using this medium. What we propose in also an exercise helping minimize 'imperialistic attitudes' at both linguistic and epistemic level.

In sum, that philosophy and science speak mainly, or solely, English is a fact. However, looking at English as a candidate Lingua Franca of scientific communication shows that this is a delusion. English is neither ethnically nor epistemological neutral, as we have shown above. Yet, we can try holding on the concept of Lingua Franca and looking for candidates that fulfil the role of the language of science. Should this language exist, we could use it scientific communication. The results of such research aren't, however, promising. It seems that there is no perfect candidate for it. Only Esperanto comes close: it is only a partially neutral language, with respect to ethnicity but not at the epistemological level. Perhaps the mistake lies in believing in the existence of a Lingua Franca. But, at this point, this seems rather an illusion. The concept of Lingua Franca hides multilingualism behind the curtain. It is high time to remove the curtain and bring multilingualism under the sunlight.

Acknowledgements This paper is the result of numerous discussions between the two of us on these (and many other) topics. Material related to multilinguism in science has been presented to 3rd-year BA students at the UvA, as part of a guest lecture by Federico Gobbo during the course 'Philosophical Approaches to the Sciences' convened by Federica Russo in the past few years. Material related to epistemic diversity has been presented by Federica Russo at the conference 'Worlds of Entanglements', held at the VUB in September 2017. We are grateful to the guest editors for encouraging us to submit our manuscript to this special issue. We are also most grateful to Moti Mizrahi, Eric Schliesser, and an anonimous reviewer for very helpful and stimulating comments. Any errors or inaccuracies remain of course ours.

Open Access This article is distributed under the terms of the Creative Commons Attribution 4.0 International License (http://creativecommons.org/licenses/by/4.0/), which permits unrestricted use, distribution, and reproduction in any medium, provided you give appropriate credit to the original author(s) and the source, provide a link to the Creative Commons license, and indicate if changes were made.

\section{References}

Airey, J., Lauridsen, K. M., Räsänen, A., Salö, L., \& Schwach, V. (2017). The expansion of English-medium instruction in the nordic countries: Can top-down university language policies encourage bottom-up disciplinary literacy goals? Higher Education, 73(4), 561-576. https://doi.org/10.1007/s10734-0159950-2. (ISSN 1573-174X).

Alcalde, J. (2015). Linguistic justice: An interdisciplinary overview of the literature. In A'dam multiling working paper 3. University of Amsterdam. http://ssrn.com/abstract=2630104.

Alcalde, J. (2018). Linguistic justice: An interdisciplinary overview of the literature (pp. 65-149). Cham: Springer. https://doi.org/10.1007/978-3-319-75263-1_2. (ISBN 978-3-319-75263-1).

Ammon, U. (1999). Deutsch als Wissenschaftssprache: die Entwicklung im 20. Jahrhundert und die Zukunftsperspektive. In H. E. Wieland (Ed.), Sprache und Sprachen in den Wissenschaften: Geschichte und Gegenwart. Berlin: de Gruyter.

Ammon, U. (Ed.). (2001). The dominance of English as a language of science: Effects on other languages and language communities. Berlin: Mouton de Gruyter.

Ammon, U. (2006). Language conflicts in the European Union. International Journal of Applied Linguistics, 16(3), 319-338. 
Andler, D. (2009). Is naturalism the unsurpassable philosophy for the sciences of man in the 21st Century? In F. Stadler, S. Hartmann, D. Dieks, W. Gonzalez, T. Uebel, \& M. Weber (Eds.), The present situation in the philosophy of science (pp. 283-303). Berlin: Springer.

Ash, M. G., \& Söllner, A. (Eds.). (2002). Forced migration and scientific change: Emigré German-speaking scientists and scholars after 1933. Cambridge: Publications of the German Historical Institute, Cambridge University Press. (ISBN 978-0-521-52278-6).

Austin, J. L. (1962). How to do things with words: The William James lectures delivered at Harvard University in 1955. Oxford: Oxford University Press.

Baird, D. (2004). Thing knowledge: A philosophy of scientific instruments. Berkeley: University of California Press. (ISBN 978-0-520-23249-5).

Barris, J. (2012). The convergent conceptions of being in mainstream analytic and postmodern continental philosophy: Convergent analytic and continental conceptions of being. Metaphilosophy, 43(5), 592618. https://doi.org/10.1111/j.1467-9973.2012.01771.x. (ISSN 00261068).

Beebee, H., \& Saul, J. (2011). Women in philosophy in the UK a report by the British Philosophical Association and the Society for Women in Philosophy UK. In: Technical report.

Boon, M. (2017). Philosophy of science in practice: A proposal for epistemological constructivism. In: Leitgeb, H., Niiniluoto, I., Seppälä, P., Sober, E. (Eds.), Logic, methodology and philosophy of science: Proceedings of the fifteenth international congress (pp. 289-310). College Publishing.

Broad, J. (2015). Women in the history of philosophy. Retrieved October 3, 2015 from https://blog.oup. com/2015/10/women-history-philosophy/.

Brosch, C. (2015). On the conceptual history of the term lingua franca. Apples, 9(1), 71-85.

Carnap R. (1932) Uberwindung der Metaphysik durch Logisce Analyse der Sprache. Erkenntnis, 2:219-241

Chalmers, D. J. (2015). Why isn't there more progress in philosophy? Philosophy, 90(1), 3-31.

Chang, H. (1999). History and philosophy of science as a continuation of science by other means. Science and Education, 8(4), 413-425. https://doi.org/10.1023/A:1008650325798.

Crystal, D. (2003). English as a global language (2nd ed.). Cambridge: Cambridge University Press.

David, M. (2016). The correspondence theory of truth. In The stanford encyclopedia of philosophy, fall 2016 edn. Metaphysics Research Lab, Stanford University. https://plato.stanford.edu/archives/fall2 016/entries/truth-correspondence/.

Davis, M. (2000). The universal computer: The road from leibniz to turing. New York: Norton.

de Kloe, F. (2016). Beyond babel: Esperanto, ido and Louis' Couturat's pursuit of an international scientific language. In W. Boyd Rayward (Ed.), Information beyond borders. Farnham: Ashgate Publishing.

Dretske, F. I. (1983). Précis of knowledge and the flow of information. Behavioral and Brain Sciences, 6(01), 55. https://doi.org/10.1017/S0140525X00014631. (ISSN 0140-525X, 1469-1825).

Dretske, F. I. (2008). Epistemology and information. In P. Adriaans \& J. Van Benthem (Eds.), Handbook of the philosophy of science, volume 8. Philosophy of information (pp. 29-47). North Holland: Elsevier.

Dutant, J. (2015). The legend of the justified true belief analysis. Philosophical Perspectives, 29(1), 95-145. https://doi.org/10.1111/phpe.12061. (ISSN 15208583).

Dutilh Novaes, C. (2015). Reductio ad absurdum from a dialogical perspective. Philosophical Studies, 173(10), 2605-2628.

D’Agostini, F. (1997). Analitici e continentali: guida alla filosofia degli ultimi trent'anni. In: S. R. Cortina (Ed.), Milano, 1 edn. ISBN 978-88-7078-424-4.

Easley, A. (1997). Toward a feminist theory of teaching argumentative writing. Feminist Teacher, 11(1), 30-38.

Eco, U. (1993). La ricerca della lingua perfetta nella cultura europea. Bari: Laterza.

Fiedler, S. (1999). Plansprache und Phraseologie Empirische: Untersuchungen zu reproduziertem Sprachmaterial im Esperanto. Bern: Peter Lang.

Fiedler, S. (2012). The Esperanto denaskulo: The status of the native speaker of Esperanto within and beyond the planned language community. Language Problems and Language Planning, 36(1), 69-84.

Floridi, L. (2004). On the logical unsolvability of the Gettier problem. Synthese, 142(1), 61-79. https://doi. org/10.1023/B:SYNT.0000047709.27594.c4.

Floridi, L. (2011a). A defence of constructionism: Philosophy as conceptual engineering: A defence of constructionism. Metaphilosophy, 42(3), 282-304. https://doi.org/10.1111/j.1467-9973.2011.01693.x. (ISSN 00261068).

Floridi, L. (2011b). The philosophy of information. Oxford: Oxford University Press.

Floridi, L. (2012). Semantic information and the network theory of account. Synthese, 184(3), 431-454. https://doi.org/10.1007/s11229-010-9821-4. (ISSN 0039-7857, 1573-0964).

Floridi, L. (2013). What is a philosophical question? Metaphilosophy, 44(3), 195-221.

Fricker, M. (2007). Epistemic injustice: Power and the ethics of knowing. Oxford: Oxford University Press. 
Gettier, E. L. (1963). Is justified true belief knowledge? Analysis, 23(6), 121-123. https://doi.org/10.1093/ analys/23.6.121. (ISSN 0003-2638, 1467-8284).

Giere, R. N. (2010). Scientific perspectivism. Chicago: University of Chicago Press. (ISBN 978-0-22629213-7 978-0-226-29212-0).

Glock, H.-J. (2008). What is analytic philosophy?. Cambridge: Cambridge University Press.

Gobbo, F. (2015). Interlinguistics, a discipline for multilingualism. Amsterdam: Amsterdam University Press.

Gobbo, F., \& Fößmeier, R. (2012). A university mainly in Esperanto. RASK Internationalt tidsskrift for sprog og kommunikation, 35, 87-106.

Gordin, M. (2015). Scientific babel. Chicago: University of Chicago Press.

Graddol, D. (2003). The decline of the native speaker. In G. Anderman \& M. Rogers (Eds.), Translation today: Trends and perspectives (pp. 152-167). Bristol: Multilingual Matters.

Haack, S. (2005). Formal philosophy? A plea for pluralism. In V. F. Hendricks \& J. Symons (Eds.), Formal philosophy (pp. 77-98). New York: Automatic Press.

Hacker, P. M. (2013). The linguistic turn in analytic philosophy. In The oxford handbook of the history of analytic philosophy.

Haslanger, S. (2008). Changing the ideology and culture of philosophy: Not by reason (alone). Hypatia, 23(2), 210-223. https://doi.org/10.1111/j.1527-2001.2008.tb01195.x. (ISSN 08875367).

Hoch, P., \& Platt, J. (1993). Migration and the denationalization of science. In E. Crawford, T. Shinn, \& S. Sörlin (Eds.), Denationalizing science the contexts of international scientific practice (pp. 133-152). Berlin: Springer. (ISBN 978-94-017-1221-7).

Horsten, L., \& Douven, I. (2008). Formal methods in the philosophy of science. Studia Logica, 89(2), 151-162. https://doi.org/10.1007/s11225-008-9129-2. (ISSN 0039-3215, 1572-8730).

Hundleby, C. (2018). Feminist perspectives on argumentation. In: Technical report. Retrieved June 21, 2019 from https://philarchive.org/archive/HUNFPO.

Hutchins, J., \& Evgenii, L. (2000). Petr petrovich troyanskii (1894-1950): A forgotten pioneer of mechanical translation. Machine Translation, 15(3), 187-221.

Hutchison, K. (Ed.). (2013). Women in philosophy: What needs to change?. New York: Oxford University Press. (ISBN 978-0-19-932561-0 978-0-19-932560-3).

Ichikawa, J. J., \& Steup, M. (2017). The analysis of knowledge. In E. N. Zalta (Ed.), The stanford encyclopedia of philosophy, fall 2017 edition. Stanford: Metaphysics Research Lab, Stanford University.

Jenkins, J. (2007). English as a Lingua Franca: Attitude and identity. Oxford: Oxford University Press.

Koehn, P. (2012). Statistical machine translation. Cambridge: Cambridge University Press.

Krachu, B. (1992). The other tongue: English across cultures. Champaign: University of Illinois Press.

Kraft, J. (2012). Justified true belief? In The epistemology of religious disagreement (pp. 9-35). New York: Palgrave Macmillan US. (ISBN 978-1-349-29414-5) 978-1-137-01510-5.

Large, A. (1985). The artificial language movement. Oxford: Blackwell.

Leitgeb, H. (2013). Scientific philosophy, mathematical philosophy, and all that. Metaphilosophy, 44(3), 267-275. https://doi.org/10.1111/meta.12029. (ISSN 00261068).

Leonelli, S. (2014). Data interpretation in the digital age. Perspectives on Science, 22(3), 397-417. https ://doi.org/10.1162/POSC_a_00140. (ISSN 1063-6145, 1530-9274).

Longino, H. E. (1987). Can there be a feminist science? Hypatia, 2(3), 51-64. https://doi. org/10.1111/j.1527-2001.1987.tb01341.x. (ISSN 08875367).

Léon, J. (2002). From universal languages to intermediary languages in machine translation: The work of the Cambridge Language Research Unit (1955-1970). In E. Guimaraes \& Barros de Pessoa (Eds.), History of linguistics (pp. 123-132). Amsterdam: John Benjamins Publishing Company.

Machery, E. (2017). Philosophy within its proper bounds. Oxford: Oxford University Press.

Massimi, M. (2009). Philosophy and the sciences after kant. Royal Institute of Philosophy Supplement, 65, 275-311. https://doi.org/10.1017/S1358246109990142. (ISSN 1358-2461, 1755-3555).

McAllister, J. (2008). Editorial: Contours of a European philosophy of science. International Studies in the Philosophy of Science, 22, 1-3.

Millgram, E. (2001). Practical reasoning: The current state of play. In E. Millgram (Ed.), Ethics done right (pp. 1-16). Cambridge: Cambridge University Peess.

Mizrahi, M. (2013). What is scientific progress? Lessons from scientific practice. Journal for General Philosophy of Science, 44(2), 375-390. https://doi.org/10.1007/s10838-013-9229-1.

Nado, J. (Ed.). (2016). Advances in experimental philosophy and philosophical methodology. London: Bloomsbury Academic.

Nersessian, N. J. (2008). Creating scientific concepts. Cambridge: MIT Press. 
Neurath, O. (1973). Wissenschaftliche Weltauffassung: Der Wiener Kreis. In M. Neurath \& R. S. Cohen (Eds.), Empiricism and sociology (pp. 299-318). Dordrecht: Springer. https://doi.org/10.1007/97894-010-2525-6_9. (ISBN 978-90-277-0259-3 978-94-010-2525-6).

Phillipson, R. (1992). Linguistic imperialism. Oxford: Oxford University Press.

Preston, A. (2010). Analytic philosophy: The history of an illusion. Continuum studies in philosophy. London: Continuum. (ISBN 978-1-4411-3196-6).

Preston, A. (Ed.). (2017). Analytic philosophy: An interpretive history. Taylor and Francis Group, New York: Routledge. (ISBN 978-1-138-80078-6 978-1-138-80079-3).

Radder, H. (1997). Philosophy and history of science: Beyond the Kuhnian paradigm. Studies in History and Philosophy of Science Part A, 28(4), 633-655. https://doi.org/10.1016/S0039-3681(97)00015 -0 . (ISSN 00393681).

Radder, H. (2017). Which scientific knowledge is a common good? Social Epistemology, 31(5), 431450. https://doi.org/10.1080/02691728.2017.1353656. (ISSN 0269-1728, 1464-5297).

Rooney, P. (2010). Philosophy, adversarial argumentation, and embattled reason. Informal Logic,. https ://doi.org/10.22329/il.v30i3.3032. (ISSN 0824-2577, 0824-2577).

Russell, B. (1989). My mental development. In P. A. Schilpp (Ed.), The philosophy of Bertrand Russell. La Salle, IL: Open Court.

Russo, F. (2016). On the poietic character of technology. Humana. Mente Journal of Philosophical Studies, $30,147-174$.

Salomone, R. (2018). Italian court pushes back on the race towards English. In University world news global edition vol. 491.

Schickore, J. (2011). More thoughts on HPS: Another 20 years later. Perspectives on Science, 19(4), $453-481$.

Schliesser, E. (2006). Philosophy and a scientific future of the history of economics. https://doi.org/10.2139/ ssrn.915941.

Schliesser, E. (2011). Four species of reflexivity and history of economics in economic policy science. https ://doi.org/10.2139/ssrn.1865185.

Schliesser, E. (2018). On philosophical translator-advocates and linguistic injustice. Philosophical Papers, 47(1), 93-121. https://doi.org/10.1080/05568641.2018.1429740.

Schuchardt, H. (1888). Auf Anlass des Volapüks. Berlin: Oppenheim.

Schuchardt, H. (1909). Die 'Lingua franca'. Zeitschrift für romanische Philologie, 33, 441-461.

Schuchardt, H. (1979). The ethnography of variation: Selected writings on pidgins and creoles. Ann Arbor: Karoma.

Searle, J. (1969). Speech acts: An essay in the philosophy of language. Cambridge: Cambridge University Press.

Seidlehofer, B. (2011). Understanding English as a Lingua Franca: A complete introduction to the theoretical nature and practical implications of English used as a lingua franca. Oxford: Oxford University Press.

Shachar, A. (2009). The Birthright Lottery. Cambridge: Harvard University Pres.

Stadler, F. (2007). History of the philosophy of science. From Wissenschaftslogik (logic of science) to philosophy of science. In General philosophy of science (pp. 577-658). Elsevier. https://doi.org/10.1016/ B978-044451548-3/50012-4 (ISBN 978-0-444-51548-3).

Stanley, J. (2011). Know how. Oxford: Oxford University Press. (ISBN 978-0-19-969536-2).

Stanley, J., \& Williamson, T. (2001). Know how. The Journal of Philosophy, 98(8), 411-444.

Steup, M. (2017). Epistemology. In E. N. Zalta (Ed.), The Stanford encyclopedia of philosophy, fall 2017 edition. Stanford: Metaphysics Research Lab Stanford University.

Stoljar, D. (2017). Philosophical progress. In Defence of a reasonable optimism. Oxford University Press.

Turri, J. (2012). Is knowledge justified true belief? Synthese, 184(3), 247-259. https://doi.org/10.1007/ s11229-010-9773-8. (ISSN 0039-7857, 1573-0964).

van Inwagen, P. (2004). Freedom to break the rules. Midwest Studies in Philosophy, 28, 334-350.

Van Inwagen, P. (2006). What is naturalism? What is analytic philosophy? In: A. Corradini, S. Galvan, E. Lowe (Eds.), Analytic philosophy without naturalism (p. Ch. 4).

Van Parijs, P. (2011). Linguistic Justice for Europe and for the World. Oxford: Oxford University Press.

van Weijen, D. (2013). Publication languages in the arts and humanities. Research Trends, 32, 20-22.

Wolters, G. (2015). Globalized parochialism: Consequences of English as Lingua Franca in philosophy of science. International Studies in the Philosophy of Science, 29(2), 189-200. https://doi. org/10.1080/02698595.2015.1119420. (ISSN 0269-8595, 1469-9281).

Publisher's Note Springer Nature remains neutral with regard to jurisdictional claims in published maps and institutional affiliations. 